\title{
Clinical Outcomes of Mitral Annuloplasty with Flexible Bands in Ischemic Mitral Regurgitation
}

\author{
Mehmet Adnan Celkan, MD, ${ }^{1}$ Ismail Kork, MD, ${ }^{1}$ Abdullah Ulucay, $\mathrm{MD}^{2}$ \\ ${ }^{1}$ Department of Cardiovascular Surgery, ${ }^{2}$ Department of Cardiology, Private Gelisim Hospital, Iskenderun, Hatay, Turkey
}

\section{ABSTRACT}

Background: In this study, we present the outcomes of 53 patients with concomitant coronary artery disease and ischemic mitral regurgitation (IMR)who underwent coronary bypass grafting (CABG) plus mitral repair (flexible posterior band annuloplasty).

Materials and Methods: A total of 53 patients with concomitant ischemic mitral regurgitation and coronary artery disease underwent CABG plus posterior mitral band annuloplasty between June 2008 and June 2015. Flexible Duran AnCore ${ }^{\circledR}$ annuloplasty band (Medtronic) was used in all patients. Transesophageal echocardiography (TEE) was intraoperatively performed in all patients. A transthoracic (TTE) follow-up examination was performed at postoperative months $1,3,6$, and 12 .

Results: The average cross-clamp and cardiopulmonary bypass times were $85.11 \pm 5.79$ and $105.98 \pm 6.14 \mathrm{~min}-$ utes, respectively. Postoperatively, there was an improvement in the grade of mitral regurgitation from 3.8 to 0.7 and in the NYHA class from $3.1 \pm 0.5$ to $0.5 \pm 0.6$ (both $\mathrm{P}<.001)$. In addition, statistically significant reductions in LVEDD, LVESD, and PAP were observed $(P<.001)$. Ejection fraction rose from $39 \pm 10 \%$ to $45 \pm 8 \%(P<.01)$. Early mortality rate was $7.5 \%(n=4)$. Mean follow-up was at 16 months. Late mortality occurred in one patient. During the follow-up period, reoperation was required in 2 patients. Only 2 parameters, redo surgery $(P=.030)$ and IABP use $(P=.021)$, were found related to mortality $(P<.001)$. Cox regression analysis showed that redo surgery and postoperative bleeding increased mortality by 14.731 times (odds ratio: $14.731 ; 95 \%$ confidence interval [CI]: 1.530-141.852) and 23.839 times (odds ratio: 23.839; 95\% CI: $1.478-348.641)$.

Discussion: In patients with IMR, mitral band annuloplasty performed in conjunction with CABG was associated with an increase in functional capacity and ejection fraction as well as a reduction in LVEDD and LVESD. This approach represents a feasible alternative with low mortality and prevents future development of mitral regurgitation and the need for redo surgery.

Received March 6, 2018; accepted May 24, 2018.

Correspondence: Mebmet Adnan Celkan; Gelisim Hastanesi, Iskenderun, Hatay, Turkey; +90-532-4355167 (e-mail: mebmetadnancelkan@gmail.com).

\section{INTRODUCTION AND OBJECTIVE}

Ischemic cardiac disease and subsequent cardiac failure due to its complications remain significant causes of morbidity and mortality, with nearly $40 \%$ of MI patients dying because of such complications (Maisel 1986). Ischemic mitral regurgitation (IMR), one such complication, may present itself with clinical manifestations of various severities, such as acute papillary muscle rupture and the subsequent cardiogenic shock, annular dilation, and left ventricular failure (Grossi 2001). Mitral regurgitation in ischemic cardiac disease is also associated with increased operative mortality (Hendren 1991).

Little is known on the optimal management of moderate and/or severe IMR during coronary bypass grafting (CABG) (Miller 2001). Recent guidelines recommend mitral valve repair to reduce symptoms and to ensure cardiac resynchronization (Gillinov 2001; Grossi 2001). In addition, clinical studies suggest that valvular repair may be undertaken with low perioperative mortality (Trichon 2003). In the long term, the risk of mortality and cardiac failure are above $50 \%$ when CABG is performed alone (Trichon 2003).

Ischemic mitral valve can be treated by using annuloplasty rings or bands concomitant with CABG. Further, the valvular coaptation may be corrected via reduction of the annular diameter (Braun 2008). Posterior band annuloplasty from trigone to trigone represents a repair option in these patients. In the current study, we aimed to present the outcomes in 53 patients with coronary artery disease and IMR who underwent CABG plus mitral repair (flexible posterior band annuloplasty).

\section{MATERIALS AND METHODS}

A total of 53 patients with concomitant IMR and coronary artery disease underwent CABG plus posterior mitral band annuloplasty between June 2008 and June 2015. The study protocol was approved by the local hospital ethics committee, and a written informed consent was obtained from each participant.

Flexible Duran AnCore ${ }^{\circledR}$ annuloplasty band (Medtronic) was used in all patients. Transesophageal echocardiography (TEE) was preoperatively performed in all patients. Patients underwent surgical management if they had annular dilation secondary to left ventricular dilation and consequent incomplete leaflet coaptation or papillary muscle dysfunction due to left ventricular remodeling (Miller 2001). These patients correspond to types 1 and 3 according to the Carpentier 
classification (Carpentier 1983). Mitral valve regurgitation (MR) was graded between 0 and 4 (none, mild, moderate, severe, and very severe in that order), and only patients with grade 3 or $4 \mathrm{MR}$ were operated upon. In addition, TEE was intraoperatively performed in all patients. Postoperative follow-up assessments with TTE were performed at months 1, 3,6 , and 12 .

After median sternotomy, a pump was initiated with aorto-arterial cannulation, bicaval venous cannulation, and antegrade cardioplegia. If required, a retrograde cardioplegia cannula was also placed. A primary procedure was performed in 44 patients and a redo surgery in 9. After cardiac arrest was achieved following cross-clamping, anastomoses were first performed in the right coronary artery and circumflex artery when required. Left anterior descending artery (LAD) anastomosis was postponed until mitral valve repair was accomplished. For annuloplasty, left atriotomy or right atrial superior septal approaches were used. For mitral exposure, an automatic mitral valve retractor was used. The valve was examined by injecting physiological saline into the left ventricle. Rupture of the chordae was also checked. Starting from the posteromedial commissure, using appropriate annuloplasty suture techniques, 2-0 polyester (Ethibond®, Ethicon ${ }^{\circledR}$, Nashville, TN, USA) sutures were used until the point of anterolateral commissure along the posterior leaflet annulus. An appropriate band was selected by measuring the intertrigonal distance and anterior leaflet dimensions. Then, the sutures were approximated by using the annuloplasty band. A physiological saline injection was used to check for leakage. Atriotomy was closed. LAD anastomosis was carried out as the last step of the procedure. After the pump was terminated, TEE was used for the assessment of all patients.

IBM SPSS Statistics 24.0 (International Business Machines Corp., Armonk, NY, US) and PAST 3 (version 3.17; Palaeontologia Electronica) programs were used to analyze the variables. For normality of univariate and multivariate data, Shapiro-Wilk and Mardia tests were used. Mann-Whitney U test was used for analysis of the quantitative data of 2 independent groups. The results of the pairedsamples t test (a parametric test) and Wilcoxon signed rank test (a nonparametric test) using bootstrap were evaluated with the Monte Carlo simulation for comparing the dependent quantitative variables and the 2 repeated measures. The Fisher exact test was compared with the exact results for comparison of categorical variables. The odds ratio was used with confidence interval (CI) to show how many times those who have a risk factor are more than those who do not. Kaplan-Meier (product limit method) and log-rank (Mantel-Cox) analyses were used to examine the effect of factors on mortality and life span. Cox regression analysis was used to assess the effects of prognostic variables on life span according to the main factor. Quantitative variables were expressed as mean \pm standard deviation (SD) and median range (maximum-minimum), and categorical variables were expressed as $\mathrm{n}(\%)$. Variables were examined at $95 \% \mathrm{CI}$, and a $P$ value of $<.05$ was considered to indicate statistical significance.
Table 1. Preoperative and Intraoperative Demographic Characteristics of Patients*

\begin{tabular}{|c|c|c|c|}
\hline & $\mathrm{N}$ & Mean \pm SD & Median (Min./Max.) \\
\hline Age & 53 & $65.09 \pm 6.33$ & $66(50 / 75)$ \\
\hline Average no. of grafts & 53 & $3.04 \pm 0.65$ & $3(2 / 5)$ \\
\hline NYHA class & 53 & $3.13 \pm 0.56$ & $3(2 / 4)$ \\
\hline CPBT, min & 53 & $105.98 \pm 6.14$ & $107(88 / 120)$ \\
\hline $\mathrm{CCT}, \min$ & 53 & $85.11 \pm 5.79$ & $86(60 / 95)$ \\
\hline \multirow[t]{2}{*}{ Mean follow-up } & 53 & $16.11 \pm 6.49$ & $16(0 / 28)$ \\
\hline & $\mathrm{n}(\%)$ & & \\
\hline \multicolumn{4}{|l|}{ Sex } \\
\hline Female & $14(26.4)$ & & \\
\hline Male & $39(73.6)$ & & \\
\hline \multicolumn{4}{|l|}{ DM } \\
\hline No & $16(30.2)$ & & \\
\hline Yes & $37(69.8)$ & & \\
\hline \multicolumn{4}{|l|}{ Redo surgery } \\
\hline No & $44(83.0)$ & & \\
\hline Yes & $9(17.0)$ & & \\
\hline \multicolumn{4}{|l|}{ Postop bleeding } \\
\hline No & $51(96.2)$ & & \\
\hline Yes & $2(3.8)$ & & \\
\hline \multicolumn{4}{|l|}{ IABP } \\
\hline No & $50(94.3)$ & & \\
\hline Yes & $3(5.7)$ & & \\
\hline \multicolumn{4}{|l|}{ Mortality } \\
\hline Alive & $48(90.6)$ & & \\
\hline Dead & $5(9.4)$ & & \\
\hline
\end{tabular}

*SD, standard deviation; Min., minimum; Max., maximum; CPBT, cardiopulmonary bypass time; CCT, cross-clamp time; NYHA class, New York Heart Association classification; IABP: intraaortic baloon pump.

\section{RESULTS}

There were 38 male and 15 female patients, with an average age of $65.09 \pm 6.33$ years. Table 1 shows the pre- and intraoperative demographic characteristics of patients. No patient had organic mitral valve disease, and all patients had least one prior myocardial infarction.

The mean cross-clamping duration was $85.11 \pm 5.79 \mathrm{~min}-$ utes, and cardiopulmonary bypass duration was $105.98 \pm$ 6.14 minutes. Concomitant with band annuloplasty, CABG was also performed in 5, 4, 3, and 2 vessels in 5, 9, 25, and 12 patients, respectively. Moreover, 2 patients underwent aortic replacement plus CABG plus band annuloplasty. The mean number of grafts was $3.04 \pm 0.65$, and 9 of these 

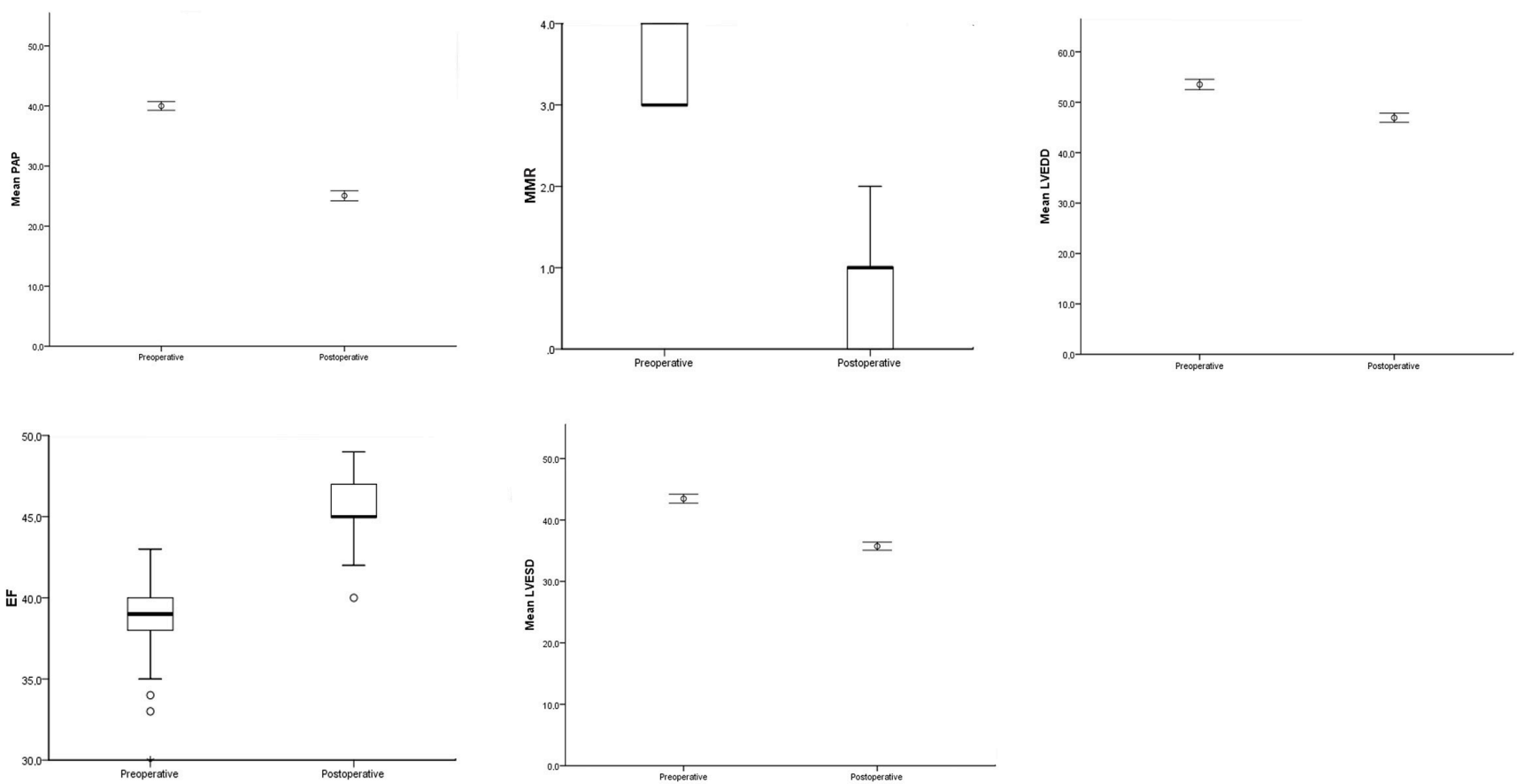

Figure 1. Preoperative and postoperative changing of patients' characteristics.

Table 2. Preoperative and Postoperative Changing of Patients' Characteristics* $†$

\begin{tabular}{|c|c|c|c|c|}
\hline & Preoperative $(N=53)$, Mean $\pm S D$ & Postoperative $(\mathrm{N}=53)$, Mean \pm SD & Change (Postop - Preop) $(N=53)$, Mean \pm SD & $P$ \\
\hline LVEDD & $53.53 \pm 3.74$ & $46.92 \pm 3.27$ & $-6.60 \pm 2.36$ & .001 \\
\hline \multirow[t]{2}{*}{ PAP } & $40.00 \pm 2.60$ & $25.06 \pm 3.05$ & $-14.94 \pm 3.03$ & .001 \\
\hline & Median (Min./Max.) & Median (Min./Max.) & Median (Min./Max.) & \\
\hline
\end{tabular}

*Test used: paired-samples $t$ test (bootstrap) and Wilcoxon signed rank test (Monte Carlo).

†SD, standard deviation; LVEDD, left ventricular end-diastolic diameter; LVESD, left ventricular end-systolic diameter; PAP, pulmonary artery pressure; Min., minimum; Max., maximum; EF, ejection fraction; MMR, mean mitral regurgitation degree.

53 patients were undergoing a reoperation. All patients had a past history of coronary bypass surgery.

Furthermore, statistically significant decline was observed in LVEDD $(53.53 \pm 3.74$ to $46.92 \pm 3.27)$, LVESD $(43.47 \pm 2.64$ to $35.74 \pm 2.37)$, and PAP $(40.00 \pm 2.60$ to $25.06 \pm 3.05)$ (Table 2 , Figure $1, P<.001)$. The grade of mitral failure was postoperatively reduced from a preoperative median value of 3 to 1 , whereas median ejection fraction improved from 39 to 45 ; both differences were statistically significant (Table $2, P<.001$ ).

Early mortality occurred in 4 patients (7.5\%), all of whom had an ejection fraction of less than $35 \%$. The causes of death included low cardiac output together with multiorgan failure. Late mortality occurred in one patient.
Tables 3 and 4 show the risk factor-related mortalities. There was no statistically significant difference between groups of alive and dead in terms of age, sex, diabetes mellitus (DM), NYHA, CPBT, CCT, average no. of grafts, LVEDD, LVESD, PAP, EF, and mean mitral regurgitation degree (MMR). However, within the alive group, LVEDD, LVESD, PAP, EF, and MMR were statistically significant (Table 3, $\mathrm{P}<$ $.001)$. Only 2 parameters, redo surgery $(P=.030)$ and IABP use $(P=.021)$, were found to be related to mortality (Table 4 , $\mathrm{P}<.001)$.

During the follow-up period, 2 patients required reoperation, one due to worsening of mitral valve (grades 3-4) at postoperative month 3 and another due to a coronary lesion. 

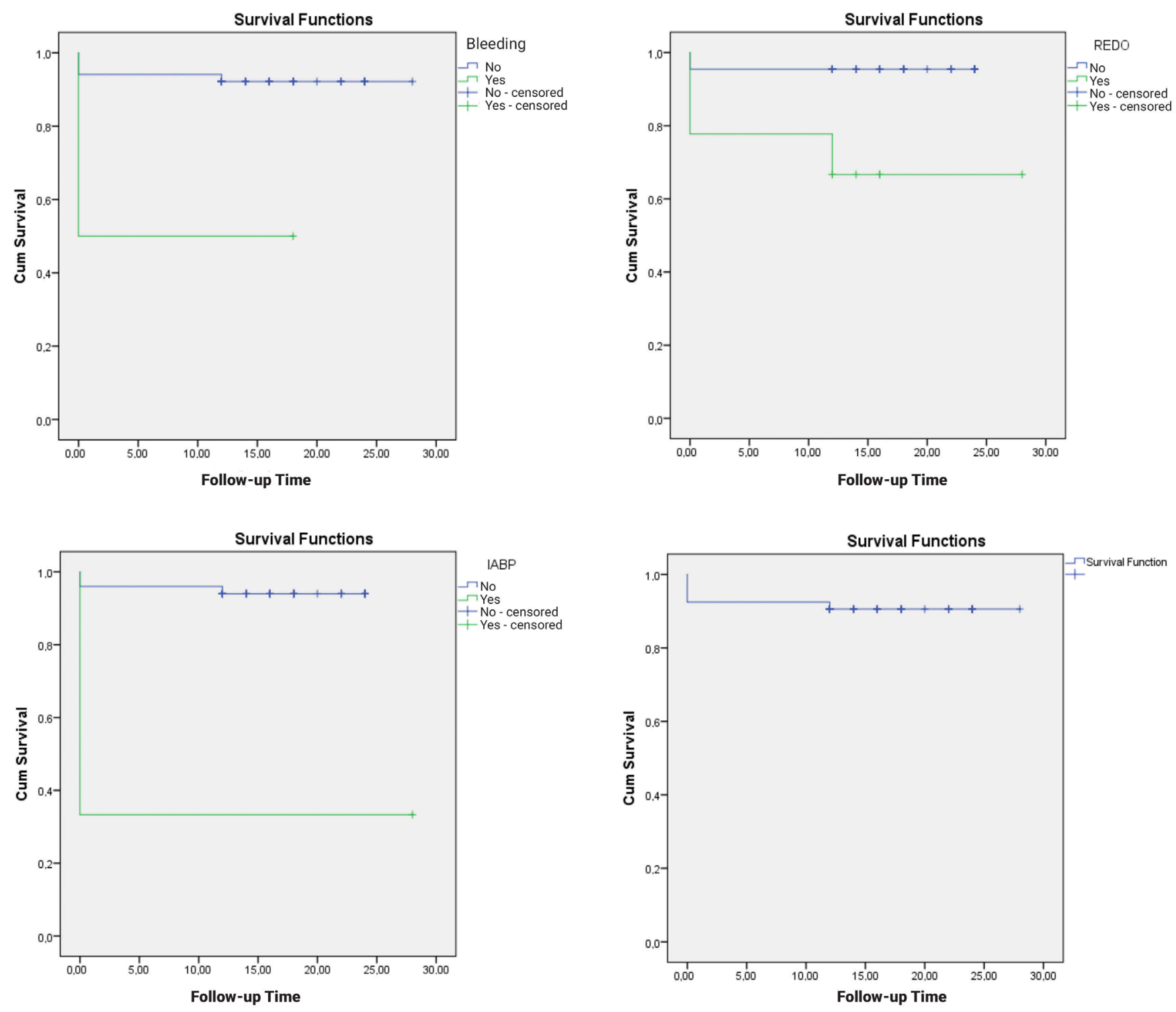

Figure 2. Life expectancy of the patients. Cum Survival, cumulative survival; REDO, redo surgery; IABP: intraaortic baloon pump.

When the results of the survival analysis were evaluated (Table 5), no statistically significant difference was found between the estimated life expectancy of women and men. In addition, no statistically significant difference was found between the estimated life expectancy of the diabetic patients and the nondiabetic patients. The estimated life expectancy of patients (Figure 2) with redo surgery, postoperative bleeding, and IABP use (20, $9,9.33$ months, respectively) was found to be statistically significantly lower than that of nonpatients $(22.9,26.04,22.8$ months, respectively) $(P=.007, P=.036, P<.001$, respectively).

Then, the parameters found to be significant in KaplanMeier test and log-rank (Mantel-Cox) analyses are considered as independent variables in Cox regression analysis. Redo surgery and postoperative bleeding increased mortality by 14.731 times (odds ratio: $14.731 ; 95 \%$ CI: $1.530-141.852$ ) and 23.839 times (odds ratio: 23.839; $95 \%$ CI: 1.478-348.641).

\section{DISCUSSION}

Mitral regurgitation developing after myocardial infarction may be classified as acute or chronic. Acute IMR culminates in hemodynamic instability and cardiogenic shock that result from volume overload due to papillary muscle rupture. Conversely, chronic IMR is a functional failure that frequently follows an inferior myocardial infarction wherein the subvalvular apparatus is normal (Kumanohoso 2003). This represents a type IIIb failure according to Carpentier's proposed classification. 
Table 3. Risk Factors-Related Mortality*†

\begin{tabular}{|c|c|c|c|}
\hline & $\begin{array}{c}\text { Alive }(n=48) \text {, } \\
\text { Median (Min./ } \\
\text { Max.) }\end{array}$ & $\begin{array}{c}\text { Dead }(n=5), \\
\text { Median (Min./ } \\
\text { Max.) }\end{array}$ & $\mathrm{P}$ \\
\hline Age, y & $66(50 / 75)$ & $66(53 / 74)$ & .828 \\
\hline Grafts, no. & $3(2 / 5)$ & $3(3 / 4)$ & .695 \\
\hline NYHA class & $3(2 / 4)$ & $3(3 / 4)$ & 1 \\
\hline CPBT, min & $107.5(88 / 120)$ & $100(100 / 110)$ & .332 \\
\hline $\mathrm{CCT}, \min$ & $85.5(60 / 95)$ & $86(80 / 90)$ & 1 \\
\hline \multicolumn{4}{|l|}{ LVEDD } \\
\hline Preoperative & $54(45 / 60)$ & $55(50 / 57)$ & .620 \\
\hline Postoperative & $46(40 / 55)$ & $45(45 / 53)$ & .969 \\
\hline Preop-to-postop change & $-7(-12 / 0)$ & $-8(-10 /-4)$ & .547 \\
\hline$P$ value within the group & $<.001$ & .064 & \\
\hline \multicolumn{4}{|l|}{ LVESD } \\
\hline Preoperative & $43(39 / 48)$ & $46(40 / 48)$ & .245 \\
\hline Postoperative & $35(32 / 40)$ & $36(32 / 43)$ & .196 \\
\hline Preop-to-postop change & $-8(-14 /-4)$ & $-8(-12 / 0)$ & .791 \\
\hline$P$ value within the group & $<.001$ & .129 & \\
\hline \multicolumn{4}{|l|}{ PAP } \\
\hline Preoperative & $40(35 / 45)$ & $38(35 / 40)$ & .015 \\
\hline Postoperative & $25(20 / 35)$ & $25(20 / 28)$ & .725 \\
\hline Preop-to-postop change & $-15(-21 /-9)$ & $-14(-18 /-7)$ & .211 \\
\hline$P$ value within the group & $<.001$ & .064 & \\
\hline \multicolumn{4}{|l|}{$\mathrm{EF}$} \\
\hline Preoperative & $40(33 / 43)$ & $35(30 / 40)$ & .021 \\
\hline Postoperative & $46(42 / 49)$ & $45(40 / 45)$ & .023 \\
\hline Preop-to-postop change & $6(2 / 10)$ & $10(2 / 12)$ & .386 \\
\hline$P$ value within the group & $<.001$ & .066 & \\
\hline \multicolumn{4}{|l|}{ MMR } \\
\hline Preoperative & $3(3 / 4)$ & $3(3 / 4)$ & .643 \\
\hline Postoperative & $1(0 / 2)$ & $0(0 / 1)$ & .627 \\
\hline Preop-to-postop change & $-3(-4 /-2)$ & $-3(-3 /-2)$ & .958 \\
\hline$P$ value within the group & $<.001$ & .065 & \\
\hline
\end{tabular}

*Tests used: Mann-Whitney $U$ test (Monte Carlo) and Wilcoxon signed rank test (Monte Carlo).

†See footnotes of Tables 1 and 2 for expansions of some abbreviations.

Pathophysiology of IMR is complex, involving the annulus, leaflets, chorda, papillary muscles, and the ventricular wall. Impairment of the papillary muscles and their attachments, ie, the ventricular wall, due to ischemia leads to wall akinesia and cavity dilation. Along with the ventricle dilation, the mitral annulus widens and thereby causes coaptation
Table 4. Risk Factor-Related Mortality and Odds Ratio* $\dagger$

\begin{tabular}{|c|c|c|c|c|}
\hline & $\begin{array}{c}\text { Alive }(n=48), \\
n(\%)\end{array}$ & $\begin{array}{c}\text { Dead }(n=5) \\
n(\%)\end{array}$ & $P$ & $\begin{array}{c}\text { Odds Ratio } \\
(95 \% \mathrm{Cl})\end{array}$ \\
\hline \multicolumn{5}{|l|}{ Sex } \\
\hline Female & $11(22.9)$ & $3(60.0)$ & 0.108 & \\
\hline Male & 37 (77.1) & $2(40.0)$ & & \\
\hline \multicolumn{5}{|l|}{ DM } \\
\hline No & $15(31.3)$ & $1(20.0)$ & 1 & \\
\hline Yes & $33(68.8)$ & $4(80.0)$ & & \\
\hline \multicolumn{5}{|c|}{ Redo surgery } \\
\hline No & $42(87.5)$ & $2(40.0)$ & $0.030 \ddagger$ & \\
\hline Yes & $6(12.5)$ & $3(60.0)$ & & $\begin{array}{c}10.5 \\
(1.4-76.3)\end{array}$ \\
\hline \multicolumn{5}{|c|}{ Postop bleeding } \\
\hline No & 47 (97.9) & $4(80.0)$ & nsa & \\
\hline Yes & $1(2.1)$ & $1(20.0)$ & & \\
\hline \multicolumn{5}{|l|}{ IABP } \\
\hline No & 47 (97.9) & $3(60.0)$ & $0.021 \ddagger$ & \\
\hline Yes & $1(2.1)$ & $2(40.0)$ & & $\begin{array}{c}31.3 \\
(2.2-452.1)\end{array}$ \\
\hline
\end{tabular}

*Test used: Fisher Exact Test.

$\dagger \mathrm{Cl}$, confidence interval; nsa, Not suitable for analysis; IABP: intraaortic baloon pump.

$\ddagger$ Parameter related to mortality.

disorder in the mitral leaflets and the consequent mitral failure (Kumanohoso 2003; Kron 2016). Subsequent ventricular remodeling displaces the papillary muscles toward the ventricular apex, which draws the chordae tendineae of a fixed length away from the line of coaptation (Boyd 2013). The retracted, not foreshortened, cordae tendineae tether the valve leaflets, with the result of prevention of normal valve closure and the presence of valvular incompetence. The leaflets appear tethered but otherwise normal (Bouma 2010).

According to the guidelines of the European Society of Cardiology and the European Association for Cardiothoracic Surgery, severe mitral regurgitation (effective regurgitating orifice area $>20 \mathrm{~mm} 2$ and regurgitating volume $30 \mathrm{~mL}$ ) should always be corrected during bypass surgery because it is associated with a poor prognosis (class I, level C) (Vahanian 2012).

Until now, various surgical methods, such as valve replacement and restrictive mitral annuloplasty, have been attempted for the management of this condition (Onorati 2009). Despite the absence of a consensus on the most effective surgical repair methodology, valvular repair is currently gaining widespread acceptance as a more effective technique (Gammie 2009). Practice guidelines recommend consideration of mitral valve repair or chordal-sparing replacement for patients with severe IMR that is causing limiting symptoms despite the best 
Table 5. Cox Regression Analysis*††

\begin{tabular}{lcccccc}
\hline & & & & & $\begin{array}{c}95 \% \text { Cl for Odds } \\
\text { Ratio }\end{array}$ \\
& B (SE) & $P$ & Odds Ratio & Lower & Upper \\
\hline Redo surgery & $2.69(1.16)$ & .020 & 14.731 & 1.530 & 141.852 \\
Postop bleeding & $3.017(1.42)$ & .025 & 23.839 & 1.478 & 384.601 \\
\hline
\end{tabular}

*Baseline hazard: 0.037 .

†Tests or models used: Cox regression-backward stepwise (Wald), Model B: regression coefficients.

$\ddagger \mathrm{Cl}$, confidence interval; SE: standard error.

available medical therapy and, possibly, cardiac resynchronization (Vahanian 2012).

Gillinov et al. reported improved outcomes with valve repair in their series involving 482 patients with IMR (Gillinov 2001). Mihaljevic and coworkers compared patients who did and did not undergo mitral valve repair with CABG and found that symptoms were less severe in the early period of mitral failure in patients undergoing valvular repair, although no significant differences were detected in the long term with regard to functional capacity and survival (Mihaljevic 2007).

Akar and colleagues reported that restrictive annuloplasty using rigid rings was their technique of choice in IMR, whereas they preferred mitral valve replacement while they were preserving the subvalvular apparatus in patients with complex (eccentric mitral regurgitation jet) ischemic mitral failure, papillary muscle infarction or rupture, and significant wall motion abnormality in the left ventricle wall (Akar 2010).

The decrease in left ventricular dimensions is particularly important with respect to ventricular remodeling, which has been previously demonstrated (Bax 2004). Although some authors advocate the use of CABG alone in patients with IMR, with an assumption that improvements in the left ventricular function would also lead to alleviation of the mitral coaptation (Tolis 2002), numerous reports contradict this approach. Many patients continue to experience residual mitral leak after CABG (Bax 2004; Kang 2006). Therefore, restrictive band annuloplasty appears to be a more effective strategy in cases with annular dilation (Lam 2005).

In a retrospective study by Lio and coworkers, no superiority of mitral repair along with coronary bypass surgery over mitral valve replacement could be demonstrated in terms of early mortality and intermediate-term survival in IMR patients with depressed left ventricular function (Lio 2014). Acker et al observed no significant difference in left ventricular reverse remodeling or 12-month survival between patients who underwent mitral valve repair and those who underwent mitral valve replacement (Acker 2014). In addition, they reported that replacement provided a more durable correction of mitral regurgitation; however, there was no significant difference in clinical outcomes (Acker 2014). Goldstein et al reported no significant difference in left ventricular reverse remodeling or 2-year survival; however, mitral regurgitation recurred more frequently in the repair group, resulting in more heart-failure-related adverse events and cardiovascular admissions (Goldstein 2016).

The dimensions of the left ventricle are an independent risk factor for mortality after mitral valve surgery. Left ventricular diameter is of primary importance in reversing the remodeling process after restrictive mitral annuloplasty. Accordingly, remodeling cannot be reversed, and residual or recurrent mitral regurgitation occurs in patients in whom the left ventricular end-diastolic diameter exceeds $65 \mathrm{~mm}$ (Braun 2005; Tribouilloy 2009).

Duran AnCore annuloplasty band with a flexible polyester structure allows the preservation of the natural geometry and motility of the mitral annulus throughout the cardiac cycle. In the current study, a flexible Duran AnCore mitral annuloplasty band was used in 53 patients with IMR, and a significant decrease in LVEDD, LVESD, PAP, and MR grade was found as documented by follow-up echocardiography performed at 6 and 12 months after the procedure. These results were also accompanied by a significant increase in EF and are in line with previous reports. IABP use, redo surgery, and postoperative bleeding were found to be major factors causing early mortality in patients. These patients mostly had low EF and diffuse coronary artery disease. In addition, their expected life span was shorter than that estimated with other diseases. Cox regression analysis revealed that patients with redo surgery and postoperative bleeding had a higher incidence of death than the other group of patients. Good preoperative evaluation is essential for patients with bleeding diathesis and redo surgery.

The most effective surgical approach to the treatment of severe IMR remains controversial. In the past few years, mitral valve repair has greatly exceeded the use of mitral valve replacement. A recent metaanalysis showed a difference in neither operative mortality nor survival when CABG with mitral valve repair was compared with moderate IMR. The major benefit from concomitant mitral valve surgery duration of CABG is associated with a greater improvement in postoperative residual mitral regurgitation and LVEF. However, the evidence establishing the advantage of combined surgery over CABG alone regarding in-hospital mortality survival and postoperative NYHA function class (Kopjar 2016; Altarabsheh 2017) is still lacking.

In conclusion, concomitant CABG and mitral band annuloplasty in patients with IMR increases the functional capacity and ejection fraction and reduces LVEDD and LVESD. This approach appears to lower the mortality rates and may also assist in reducing future occurrences of mitral failure and the need for redo surgery.

\section{REFERENCES}

Acker MA, Parides MK, Perrault LP, et al. 2014. Mitral valve repair versus replacement for severe ischemic mitral regurgitation. $\mathrm{N}$ Engl J Med 370: 23-32.

Akar AR, Durdu S, Zaim C, et al. 2010. [Clinical outcome and factors affecting surgical decision for repair versus replacement in patients with mitral regurgitation]. Anadolu Kardiyol Derg 10:358-66. Turkish. 
Altarabsheh SE, Deo SV, Dunlay SM, et al. 2017. Meta-analysis of usefulness of concomitant mitral valve repair or replacement for moderate ischemic mitral regurgitation with coronary artery bypass grafting. Am J Cardiol 119:734-41.

Bax JJ, Braun J, Somer ST, et al. 2004. Restrictive annuloplasty and coronary revascularization in ischemic mitral regurgitation results in reverse left ventricular remodelling. Circulation 110(11 suppl 1):II103-8.

Braun J, Bax JJ, Versteegh MI, et al. 2005. Preoperative left ventricular dimensions predict reverse remodeling following restrictive mitral annuloplasty in ischemic mitral regurgitation. Eur J Cardiothorac Surg 27:847-53.

Braun J, van de Veire NR, Klautz RJ, et al. 2008. Restrictive mitral annuloplasty cures ischemic mitral regurgitation and heart failure. Ann Thorac Surg 85:430-436; discussion 436-7.

Bouma W, van der Horst I, Wijdh-den Hamer I, et al. 2010. Chronic ischemic mitral regurgitation. Current treatment results and new mechanism based surgical approaches. Eur J Cardiothorac Surg 37:170-85.

Boyd JH. 2013. Ischemic mitral regurgitation Circ J 77:1952-56.

Carpentier A. 1983. Cardiac valve surgery--the "French correction." J Thorac Cardiovasc Surg 86:323-37.

Gammie JS, Sheng S, Griffith BP, et al. 2009. Trends in mitral valve surgery in the United States: results from the Society of Thoracic Surgeons Adult Cardiac Surgery Database. Ann Thorac Surg 87:1431-7.

Gillinov AM, Wierup PN, Blackstone EH, et al. 2001. Is repair preferable to replacement for ischemic mitral regurgitation? J Thorac Cardiovasc Surg 122:1125-41.

Goldstein D, Moskowitz AJ, Gelijns AC, et al. 2016. Two-year outcomes of surgical treatment severe ischemic mitral regurgitation. N Engl J Med 374: 344-53.

Grossi EA, Goldberg JD, LaPietra A, et al. 2001. Ischemic mitral valve reconstruction and replacement: comparison of long-term survival and complications. J Thorac Cardiovasc Surg 122:1107-24.

Hendren WG, Nemec JJ, Lytle BW, et al. 1991. Mitral valve repair for ischemic mitral insufficiency. Ann Thorac Surg 52:1246-52.

Kang DH, Kim MJ, Kang SJ, et al. 2006. Mitral valve repair versus revascularization alone in the treatment of ischemic mitral regurgitation. Circulation 114(1 suppl):I499-503.

Kopjar T, Gasparovic H, Mestres CA, Milicic D, Biocina B. 2016. Metaanalysis of concomitant mitral valve repair and coronary artery bypass surgery versus isolated coronary artery bypass surgery in patients with moderate ischaemic mitral regurgitation. Eur J Cardiothorac Surg 50:212-222.

Kron IL, Acker MA, Adams DH, et al. 2016. 2015 The American Association for Thoracic Surgery Consensus Guidelines: Ischemic mitral valve regurgitation. J Thorac Cardiovasc Surg 151:940-56.
Kumanohoso T, Otsuji Y, Yoshifuku S, et al. 2003. Mechanism of higher incidence of ischemic mitral regurgitation in patients with inferior myocardial infarction: quantitative analysis of left ventricular and mitral valve geometry in 103 patients with prior myocardial infarction. J Thorac Cardiovasc Surg 125:135-43.

Lam BK, Gillinov AM, Blackstone EH, et al. Importance of moderate ischemic mitral regurgitation. Ann Thorac Surg, 2005; 79: 462-470.

Lio A, Miceli A, Varone E, et al. 2014. Mitral valve repair versus replacement in patients with ischaemic mitral regurgitation and depressed ejection fraction: risk factors for early and mid-term mortality. Interact Cardiovasc Thorac Surg 19:64-9.

Maisel AS, Gilpin EA, Klein L, Le Winter M, Hennimg H, Collins D. 1986. The murmur of papillary muscle dysfunction in acute myocardial infarction: clinical features and prognostic implications . Am Heart J 112:705-11.

Mihaljevic T, Lam BK, Rajeswaran J, et al. 2007. Impact of mitral valve annuloplasty combined with revascularization in patients with functional ischemic mitral regurgitation. J Am Coll Cardiol 49:2191-201.

Miller DC. 2001. Ischemic mitral regurgitation redux - to repair or to replace? J Thorac Cardiovasc Surg 122:1059-62.

Onorati F, Rubino AS, Marturano D, et al. 2009. Mid-term echocardiographic results with different rings following restrictive mitral annuloplasty for ischaemic cardiomiopathy [sic]. Eur J Cardiothoracic Surg, 36:250-60

Tolis GA Jr, Korkolis DP, Kopf GS, Elefteriades JA. 2002. Revascularization alone (without mitral valve repair) suffices in patients with advanced ischemic cardiomyopathy and mild-to-moderate mitral regurgitation. Ann Thorac Surg, 74:1476-80; discussion 1480-1.

Tribouilloy C, Grigioni F, Avierinos JF, et al. 2009. Survival implication of left ventricular end-systolic diameter in mitral regurgitation due to flail leaflets: a long-term follow-up multicenter study. J Am Coll Cardiol 54:1961-68.

Trichon BH, Glower DD, Shaw LK, et al. 2003. Survival after coronary revascularization, with and without mitral valve surgery in patients with ischemic mitral regurgitation. Circulation 108(supp 1):II103-10.

Vahanian A, Alfieri O, Andreotti F, et al. 2012. Guidelines on the management of valvular heart disease (version 2012): the Joint Task Force on the Management of Valvular Heart Disease of the European Society of Cardiology (ESC) and the European Association for Cardio-Thoracic Surgery (EACTS). Eur Heart J 33:2451-96.

Vahanian A, Alfieri O, Andreotti F, et al. 2012. Guidelines on the management of valvular heart disease (version 2012): the Joint Task Force on the Management of Valvular Heart Disease of the European Society of Cardiology (ESC) and the European Association for Cardio-Thoracic Surgery (EACTS). Eur J Cardiothorac Surg 42:S1-44. 